\title{
FEDERALISMO AMBIENTAL COOPERATIVO E MÍNIMO EXISTENCIAL SOCIOAMBIENTAL: a multidimensionalidade do bem-estar como fio condutor
}

Rogério Santos Rammê Doutorando em Direito pela Pontifícia Universidade Católica do Rio Grande do Sul - PUCRS
(área de concentração: Fundamentos Constitucionais do Direito Público e do Direito Privado).
Mestre em Direito pela Universidade de Caxias do Sul - UCS (área de concentração: Direito
Ambiental e Sociedade). Especialista em Direito Ambiental pela Universidade Luterana do
Brasil - ULBRA. Graduado em Direito pela Pontifícia Universidade Católica do Rio Grande
do Sul - PUC/RS. Assessor Jurídico no Tribunal de Justiça do Rio Grande do Sul - TJ/RS.
Membro da Rede Brasileira de Justiça Ambiental (RBJA). Tem experiência na área do Direito,
com ênfase em Direito Ambiental. Professor convidado em cursos
de extensão e especialização em Direito Ambiental.
End. eletrônico: rogerioramme@hotmail.com

\section{RESUMO}

Este artigo objetiva analisar a importância da compreensão da multidimensionalidade do bem-estar para uma redefinição do conteúdo normativo da noção de mínimo existencial socioambiental, traçando, a partir dessa redefinição, novos ares de compreensão sobre o federalismo ambiental cooperativo brasileiro. Adotou-se o método dialético de abordagem, a partir de aportes doutrinários. Dessa forma, foi possível verificar que o Estado de Direito contemporâneo se depara com dois desafios centrais: superar as desigualdades econômicas e as injustiças ambientais. Para enfrentá-los, países como o Brasil, que adotam o modelo federativo, devem priorizar soluções sistêmicas e cooperativas entre os entes da federação. A cooperação federativa que norteia as políticas públicas socioambientais no Brasil deve ter como referência as noções paradigmáticas de mínimo existencial e de bem-estar socioambiental. Os deveres de proteção do Estado em matéria socioambiental decorrentes do atual marco normativo constitucional 
brasileiro incorporam, assim, o referencial não menos paradigmático da sustentabilidade como seu objetivo fundamental.

Palavras-chave: Estado de Direito. Cooperação federativa. Mínimo existencial. Sustentabilidade. Direitos fundamentais socioambientais.

\title{
ENVIRONMENTAL COOPERATIVE FEDERALISM AND SOCIO- ENVIRONMENTAL EXISTENTIAL MINIMUM: the multidimensionality of welfare like conducting wire
}

\begin{abstract}
This paper aims to analyze the importance of understanding the multidimensionality of welfare for a redefinition of the normative content of the notion of socio-environmental existential minimum, tracing, from this redefinition, a new understanding about the Brazilian cooperative environmental federalism. It was adopted dialectical method of approach, from doctrinal contributions. Thus, it was possible to verify that the contemporary Rule of Law faces two central challenges: overcoming economic inequalities and environmental injustices. To face them, countries like Brazil, that adopt the federative model, should prioritize systemic and cooperatives solutions in the Federation. The federal cooperation that guides socioenvironmental public policies in Brazil shall be by reference the paradigmatic notions of socio-environmental existential minimum and well-being. The duties of state protection in environmental matters arising out of the current Brazilian constitutional legal framework incorporate thus the referential no less paradigmatic of sustainability as its primary aim.
\end{abstract}

Keywords: Rule of Law; Federal cooperation; Existential minimum; Sustainability; Socio-environmental fundamental rights. 


\section{INTRODUÇÃO}

O Estado de Direito Brasileiro, no que tange à proteção e garantia de direitos fundamentais, vem atravessando um momento de crise e de contestação por parte da população brasileira.

A reivindicação por direitos cresce no cenário social brasileiro a cada dia, no ritmo da globalização e das novas redes de conexão interpessoal de informação instantânea, desenvolvidas a partir do surgimento das novas tecnologias da informação e da comunicação. Não se trata de fenômeno exclusivamente brasileiro. Ao contrário, ao que tudo indica, trata-se de uma onda mundial de protestos populares que chegou ao Brasil. Com atraso até, dirão alguns. Ela nasce, essencialmente, fruto da reivindicação por direitos fundamentais cuja eficácia o Estado de Direito Brasileiro não vem conseguindo assegurar à população.

A proteção do direito fundamental ao ambiente ecologicamente equilibrado no Brasil, igualmente, é uma quimera. Indicadores de sustentabilidade e de bem-estar socioambiental não são sequer considerados nas decisões executivas da política socioambiental brasileira.

Levando em consideração esses aspectos, o presente ensaio procura analisar a possibilidade de traçar uma delimitação mais clara sobre o conteúdo normativo da noção de mínimo existencial socioambiental a partir de uma abordagem multidimensional do bem-estar, bem como tecer considerações sobre sua efetiva concretização no âmbito do federalismo cooperativo brasileiro que marca o exercício da competência administrativa em matéria ambiental, sobretudo após o advento da Lei Complementar n. $140 / 2011$.

Para além do plano meramente discursivo, a Ciência do Direito vê-se desafiada a produzir, no campo normativo, contribuições efetivas e concretas para a tutela dos direitos fundamentais, capazes de moldar a política, regular a economia e garantir o bem-estar social e ambiental. Contribuições que reorientem o Estado de Direito brasileiro com foco no futuro. Essa a motivação que conduziu as linhas que seguem.

\section{ESTADO DE DIREITO E MULTIDIMENSIONALIDADE DO BEM-ESTAR: CONTRIBUTOS PARA A NOÇÃO DE MÍNIMO EXISTENCIAL SOCIOAMBIENTAL}

A noção de Estado de Direito vem assumindo um papel cada vez 
mais importante e decisivo no cenário jurídico-político contemporâneo. De um conceito predominantemente doutrinário, orientador da ciência do Direito Público, o Estado de Direito transmuta-se, sobretudo a partir da segunda metade do século XX, em um conceito principiológico, reorientador do sistema jurídico-político da maioria dos países liberais.

A esse respeito, Jaques Chevalier ${ }^{1}$ assinala que passada a Segunda Guerra Mundial a noção de Estado de Direito deixa de traduzir a simples ideia de um sistema de articulação de normas juridicamente hierarquizadas, assumindo uma dimensão ampliada que incorpora um conjunto de direitos e liberdades substanciais. O Estado de Direito, desde então, passa a se assentar em aspectos formais e substanciais indissociáveis, destacados por Chevalier':

[...] a hierarquia das normas já não é concebida como uma simples polícia interna da ordem jurídica, mas como um meio de proteção dos direitos fundamentais; o aperfeiçoamento da arquitetura formal é posto a serviço de exigências mais profundas, de natureza substancial.

Com efeito, a arquitetura formal dessa nova concepção de Estado de Direito, desenvolvida a partir da metade do século XX, aperfeiçoa-se por meio de uma ampliação do conceito de legalidade, que passa a ser concebida pela perspectiva que incorpora não apenas a Constituição e legislação infraconstitucional a ela conforme, mas também os tratados internacionais, princípios e valores incorporados ao sistema jurídico. Aperfeiçoa-se, também, pela submissão da administração a essa noção ampla de legalidade, pelo reforço da independência dos juízes e pela garantia de um efetivo controle de constitucionalidade das leis ${ }^{3}$.

Além disso, o Estado de Direito assume, a partir de então, as características de "social e democrático", materialmente aberto a uma pluralidade de concretizações norteadas por três elementos centrais, assim sintetizados por Jorge Reis Novaes": "[...] a segurança jurídica que resulta da proteção dos direitos fundamentais, a obrigação social de configuração da sociedade por parte do Estado e a autodeterminação democrática".

Contudo, profundas transformações econômicas e políticas glo-

${ }^{1}$ CHEVALIER, 2013, p. 59-60.

${ }^{2}$ CHEVALIER, 2013, p. 60.

${ }^{3}$ CHEVALIER, 2013.

${ }^{4}$ NOVAIS, 2006, p. 210. 
bais, ocorridas no final do século $\mathrm{XX}$, ocasionaram significativas alterações nas estruturas de poder, trabalho, riqueza, produção, comércio, fluxos de informações, as quais ultrapassam os tradicionais limites dos Estados nacionais. Tal situação impôs novos desafios ao Estado de Direito contemporâneo, pondo em cheque sua estrutura normativa até então concebida. Contudo, dois deles são centrais.

O primeiro desafio imposto ao Estado de Direito é o da superação da desigual distribuição do poder econômico no cenário social. Afinal, uma desigual distribuição do poder econômico gera poder político aos mais ricos, os quais utilizam esse poder para condicionar o Estado de Direito em seu benefício, gerando mais desigualdade e exploração.

A esse respeito, Joseph E. Stiglitz ${ }^{5}$ assevera que cada vez mais os ricos usam seu poder político para condicionar o Estado de Direito, com o objetivo de consolidar marcos normativos que lhes permitam seguir explorando os mais pobres, garantindo assim a manutenção das desigualdades e das injustiças decorrentes dessa exploração econômica. Dessa forma, determinados grupos econômicos poderosos, por meio de lobbys e financiamento de campanhas eleitorais, acabam controlando o processo político e o utilizando para moldar um sistema econômico cada vez mais favorável a seus interesses. Fruto desse controle e pressão política que os detentores do poder econômico exercem, são aprovadas leis e normativas que conformam o Estado de Direito aos interesses dos mais ricos ${ }^{6}$.

Essa submissão do poder político ao poder econômico é, portanto, uma forte ameaça às conquistas do Estado de Direito contemporâneo e um de seus desafios centrais.

O segundo importante desafio que se apresenta ao Estado de Direito contemporâneo é o da superação da desigual distribuição da degradação ambiental no espaço coletivo. Um desafio que também decorre da submissão do poder político ao poder econômico, mas que apresenta um viés específico, socioambiental: o da destinação da maior carga dos danos e riscos ambientais decorrentes do processo de desenvolvimento a certas comunidades tradicionais, grupos de trabalhadores, grupos raciais discriminados, populações pobres, marginalizadas e vulneráveis.

Trata-se, portanto, de um desafio por justiça ambiental, que está a exigir do Estado de Direito contemporâneo a superação das desigualdades

$\overline{{ }^{5} \text { STIGLITZ, 2012, p. } 253 .}$

${ }^{6}$ STIGLITZ, 2012. 
sociais e ambientais por meio de instrumentos jurídico-políticos capazes de impedir toda e qualquer espécie de violações de direitos fundamentais originadas em contextos de degradação ambiental. Corrobora tal afirmação a posição de José Joaquim Gomes Canotilho ${ }^{7}$, para quem "[...] a justiça aponta para as exigências de igualdade, sob pena de os riscos ambientais representados por indústrias, resíduos, descargas, serem deslocados para zonas deprimidas ou para Estados sem defesas ecológicas."

Como se percebe, os desafios da superação das desigualdades econômicas e das injustiças ambientais exigem soluções sistêmicas, cooperativas, conjuntas. Algumas delas passam por novos mecanismos de regulação do mercado; por políticas públicas voltadas à distribuição de renda; pela adoção de um novo modelo de desenvolvimento (e não mero crescimento econômico), pautado por indicadores capazes de avaliar o bem-estar da população em suas mais distintas dimensões. Outras delas vinculam-se à velha ideia do "agir local e pensar global", respeitando as diversidades regionais, culturais, ambientais etc. Todas, porém, passam pela garantia do bem-estar socioambiental individual e coletivo em suas múltiplas dimensões.

Essa multidimensionalidade do bem-estar, objeto focal do Estado de Direito contemporâneo, abrange, segundo Stigliz, Sen e Fitoussi ${ }^{8}$ : a) padrões de vida materiais (renda, consumo e riqueza); b) saúde; c) educação; d) atividades pessoais, incluindo o trabalho; e) voz política e governança; f) conexão social e relacionamentos; g) meio ambiente (condições presentes e futuras); h) segurança (física e econômica).

Com efeito, a multidimensionalidade do bem-estar como fio condutor do agir estatal acarreta, como corolário, a incorporação da sustentabilidade como paradigma axiológico do Estado de Direito contemporâneo. Essa relação entre sustentabilidade e bem-estar também é acentuada por Juarez Freitas 9 :

\footnotetext{
Na sociedade de risco mundial, na qual não mais podem ser negligenciadas as consequências involuntárias (externalidades) e a dramaticidade das questões ambientais lato sensu, (notadamente as causadas por atuação e omissão humanas), é irrenunciável que o conceito de sustentabilidade insira a multidimensionalidade do bem-estar como opção deliberada pelo reequilíbrio dinâmico a favor da vida.
}

${ }^{7}$ CANOTILHO, 1999, p. 45.

${ }^{8}$ STIGLIZ; SEN; FITOUSSI, 2009.

${ }^{9}$ FREITAS, 2012, p. 49. 
Ademais, a constatação de Freitas de que a sustentabilidade é multidimensional, justamente porque o bem-estar também o é, pode contribuir consideravelmente em temáticas que vêm sendo abordadas por autores que analisam a proteção jurídica do meio ambiente a partir da Teoria dos Direitos Fundamentais.

Expoentes dessa perspectiva, Ingo Wolfgang Sarlet e Tiago Ferstenseifer ${ }^{10}$ destacam o recente surgimento de um constitucionalismo socioambiental, que avança para além das conquistas de um constitucionalismo social, inserindo em seu marco normativo anseios de correção do quadro de desigualdade e degradação humana em termos de acesso às mínimas condições de bem-estar. Referidos autores também defendem que a opção da sustentabilidade, em países como o Brasil, passa necessariamente pela correção do quadro alarmante de desigualdade social e da falta de acesso a direitos sociais básicos da população. ${ }^{11}$

Tomando por base a Teoria dos Direitos Fundamentais, consolidam-se no cenário jurídico-doutrinário brasileiro as noções de dimensão ecológica da dignidade humana, fruto do reconhecimento de que qualidade do ambiente (que deverá ser sadio e equilibrado ecologicamente) é vital para o desenvolvimento humano em níveis dignos; e de mínimo existencial socioambiental, que traduz a garantia de um patamar mínimo de qualidade e segurança ambiental compatível com a dignidade que é inerente à vida humana. Em outras palavras, um patamar mínimo de bem-estar socioambiental, numa visão integrada, ecológica, sistêmica, das relações entre o homem e seu entorno ${ }^{12}$.

A noção de mínimo existencial socioambiental (ou ecológico, como preferem alguns) ganha, assim, significativa importância no atual marco normativo constitucional. Referida noção traduz a necessidade do atendimento das necessidades básicas de todos, sendo importante não confundir, como bem assinala Carlos Alberto Molinaro ${ }^{13}$ :

\footnotetext{
[...] as necessidades que são inerentes à condição humana, com as necessidades básicas do ser humano. As primeiras estão impressas no biológico e no psíquico; já as segundas são resultado de um modelo social político e econômico arquitetado pela deformação do cultural.
}

${ }^{10}$ SARLET; FENSTERSEIFER, 2010, p. 13.

${ }^{11}$ SARLET; FENSTERSEIFER, 2010.

${ }^{12}$ SARLET; FENSTERSEIFER, 2013.

${ }^{13}$ MOLINARO, 2007, p. 95-96. 
Conjugando tais perspectivas, o que aqui se pretende afirmar é que a multidimensionalidade do bem-estar pode ser um caminho apto a identificar o preenchimento do núcleo duro, essencial, do mínimo existencial socioambiental. Afinal, como bem ressaltam Sarlet e Fensterseifer ${ }^{14}$, não se pode confundir o mínimo existencial como algo como um "mínimo vital" ou "mínimo de sobrevivência". Por isso a multidimensionalidade do bem-estar contribui para a conformação normativa do mínimo existencial socioambiental, de modo a buscar sua concretude e exequibilidade em um Estado de Direito, socioambiental e sustentável, de fato.

Com efeito, a partir da união das referidas perspectivas, acredita-se ser possível delimitar a noção de mínimo existencial socioambiental como sendo o direito-garantia que vincula os particulares e obriga o Estado de Direito (deveres de proteção) a assegurar a todos um patamar mínimo de qualidade socioambiental para a concretização de uma existência digna, o qual pode ser medido a partir das múltiplas dimensões do bem-estar (socioambiental), que abrangem: a) padrões de vida materiais; b) saúde; c) educação; d) atividades pessoais; e) voz política e governança; f) conexão social e relacionamentos; g) meio ambiente presente e futuro; $h$ ) segurança física e econômica.

A seguir buscar-se-á analisar se o Estado de Direito brasileiro, que adota um sistema federativo do tipo "cooperativo", sobretudo no exercício da competência administrativa em matéria ambiental, alinha-se à perspectiva acima desenvolvida.

\section{O MÍNIMO EXISTENCIAL SOCIOAMBIENTAL COMO OBJE- TIVO FUNDAMENTAL DA COOPERAÇÃO ENTRE OS ENTES FEDERATIVOS NO EXERCÍCIO DA COMPETÊNCIA ADMINIS- TRATIVA EM MATÉRIA AMBIENTAL}

De plano, cumpre delimitar o objeto da análise que segue: pretende-se, na sequência, examinar se - no âmbito da competência administrativa (ou executiva) em matéria ambiental, regulamentada recentemente por meio da Lei Complementar n. 140/2011 - existem referenciais que norteiem a cooperação federativa com vistas à garantia do mínimo existencial socioambiental.

Antes, porém, importa traçar, em linhas gerais, a noção básica

${ }^{14}$ SARLET; FENSTERSEIFER. 2013, p. 127. 
de federalismo, bem como tecer algumas considerações sobre o modelo de federalismo cooperativo adotado pelo Brasil a partir da Constituição Federal de 1988.

A história e a origem do federalismo moderno mantêm uma estreita relação com o constitucionalismo norte-americano, consolidado a partir da promulgação da Constituição Americana de 1789. Na opinião de Paulo José Leite Farias ${ }^{15}$ :

\footnotetext{
A Federação moderna é invenção dos pais da Constituição americana, que, para tanto, evidentemente, também esquadrinharam a história. Desde então, surgiram, regularmente, em outros países de todas as partes do mundo, constituições federalistas a partir do, e em oposição ao, modelo clássico americano.
}

$\mathrm{Na}$ atualidade, praticamente todas as democracias de grande extensão territorial e com grandes populações são federações. Apesar disso, as federações apresentam diferenças significativas quanto à composição social, econômica e institucional. Seus arranjos institucionais internos também variam. Algumas federações são altamente centralizadas, concentrando o poder no nível federal de governo - embora essa denominação não seja sempre utilizada - enquanto outras federações se baseiam em modelos mais descentralizados, conferindo significativas parcelas de poder às unidades federativas. Contudo, uma característica essencial é comum em todos os Estados federalistas: a existência de no mínimo dois níveis de governo constitucionalmente instituídos, cada qual dotado de genuína autonomia uma em relação à outra e responsáveis perante os respectivos eleitores ${ }^{16}$.

Como salientado ao início, o Brasil, com a Carta de 1988, adotou claramente a forma de um federalismo cooperativo, o qual representa, segundo Andreas J. Krell ${ }^{17}$, o modelo ideal para as relações intergovernamentais, baseado no compartilhamento de tarefas entre os níveis de governo, exigindo mecanismos capazes de viabilizar ações e políticas conjuntas, bem como a participação de todos os entes federativos.

Isso ficou ainda mais evidente após a inserção do Artigo 241 no texto da Constituição Federal brasileira, com redação determinada pela

\footnotetext{
${ }^{15}$ FARIAS, 1999, p. 38.

${ }^{16}$ ANDERSON, 2009, p. 17-20.

${ }^{17}$ KRELL, 2008, p. 47.
} 
Emenda Constitucional n. 19/1998. Na opinião de Krell ${ }^{18}$, desde então o federalismo cooperativo brasileiro objetiva "[...] sintonizar e racionalizar as ações dos diferentes níveis de governo através da construção de um consenso político e administrativo".

O federalismo cooperativo adotado no Brasil nasceu inspirado no modelo federativo alemão estabelecido com a Lei Fundamental de Bonn de 1949, que rompeu com o tradicional federalismo dual de influência norte-americana. A Lei Fundamental alemã inovou ao estabelecer um sistema de repartição de competências que se baseava muito mais na cooperação entre a instância federal (Bund) e as instâncias estaduais (Länder) do que na separação, independência e autonomia típicos do modelo dual estadunidense ${ }^{19}$.

A conclusão de um recente estudo comparativo sobre os modelos de repartição de competências legislativas e administrativas nos estados federados, de autoria de Fabrício Ricardo de Limas Tomio, Marcelo Augusto Biehl Ortolan e Fernando Santos Camargo ${ }^{20}$, que teve como foco os sistemas federativos alemão, argentino, australiano, austríaco, suíço, brasileiro, indiano e estadunidense, aponta o sistema federativo alemão, sobretudo após as mudanças implementadas pela Reforma Federativa de 2006, com a eliminação das clássicas competências legislativas "de quadro", como o mais equilibrado dentre os analisados. Isso porque, em matérias essenciais como soberania, economia e políticas públicas, a federação alemã não é demasiadamente descentralizada tampouco excessivamente centralizada, ao contrário dos demais países estudados, implicando assim uma maior cooperação federativa.

O modelo de repartição de competências (legislativas e administrativas) adotado no Brasil teve, pois, inspiração no sistema germânico: no âmbito legislativo, salvo as matérias em que é estabelecida a competência privativa da União, uma boa parte das matérias fica a cargo da União para elaboração de normas gerais, enquanto aos estados federados e aos municípios brasileiros - estes últimos com espaço de atuação mais restrito - cabe a suplementação; no âmbito administrativo são previstas, sem prejuízo às matérias restritas à competência geral da União, competências comuns entre todos os entes da federação, implicando um verdadeiro federalismo cooperativo de execução.

\footnotetext{
${ }^{18}$ KRELL, 2008, p. 14.

${ }^{19}$ KRELL, 2008.

${ }^{20}$ TOMIO; ORTOLAN; CAMARGO, 2010.
} 
Não se pretende aqui tecer uma análise pormenorizada das competências ambientais constitucionais, já que não é este o objetivo do presente ensaio. Busca-se aqui, como salientado alhures, analisar se, com o advento da Lei Complementar n. 140/2011 - que regulamentou, no plano infraconstitucional, a cooperação entre a União, os Estados, o Distrito Federal e os Municípios nas ações administrativas decorrentes do exercício da competência comum em matéria ambiental - o federalismo cooperativo (de execução) brasileiro tutela a garantia de um mínimo existencial socioambiental.

A Lei Complementar em questão não passou isenta de críticas pela doutrina especializada. Toshio Mukai ${ }^{21}$, por exemplo, sustenta a inconstitucionalidade do parágrafo $2^{\circ}$ do Artigo $4^{\circ}$ da Lei Complementar n. 140/2011, que dá a composição da Comissão Tripartite Nacional (representantes dos Poderes Executivos da União, dos Estados, do DF e dos Municípios, paritariamente). Já Paulo Affonso Leme Machado ${ }^{22}$ sustenta que o estabelecimento da tipologia pelo Poder Executivo para o licenciamento ambiental e a tipologia definida pelos Conselhos Estaduais do Meio Ambiente violam o Artigo 170, parágrafo único, da Constituição Federal brasileira, que assegura a todos o livre exercício de atividades econômicas, independente de autorização de órgãos públicos.

Críticas à parte, a Lei Complementar n. 140/2011 trouxe inegáveis avanços em termos de cooperação entre os entes federativos. Trata-se de diploma legal que, segundo ressaltam Sarlet e Fensterseifer ${ }^{23}$, incorporou definitivamente o Princípio da Cooperação no ordenamento jurídico pátrio. Ainda, o referido diploma legal definiu de modo bastante taxativo as competências administrativas de cada ente federativo na tutela do ambiente, bem como estabeleceu os instrumentos para a cooperação federativa, tais como: consórcios públicos; convênios, acordos de cooperação técnica e outros instrumentos similares com órgãos e entidades do Poder Público; as Comissões Tripartites Nacional e Estaduais e a Comissão Bipartite do Distrito Federal; fundos públicos e privados e outros instrumentos econômicos; a possibilidade de delegação de atribuições de um ente federativo a outro; dentre outros.

Mas a questão que não pode passar despercebida são os objetivos fundamentais do exercício da competência (executiva) comum em matéria

\footnotetext{
${ }^{21}$ MUKAI, 2011.

${ }^{22}$ MACHADO, 2013, p. 189.

${ }^{23}$ SARLET; FENSTERSEIFER, 2013, p. 186.
} 
ambiental elencados nos quatro incisos do Art. $3^{\circ}$ da Lei Complementar n. 140/2011: a) proteger, defender e conservar o meio ambiente ecologicamente equilibrado, promovendo a gestão descentralizada, democrática e eficiente; b) garantir o equilíbrio do desenvolvimento socioeconômico com a proteção do meio ambiente, observando a dignidade da pessoa humana, a erradicação da pobreza e a redução das desigualdades sociais e regionais; c) harmonizar as políticas e ações administrativas para evitar a sobreposição de atuação entre os entes federativos, de forma a evitar conflitos de atribuições e garantir uma atuação administrativa eficiente; d) garantir a uniformidade da política ambiental para todo o País, respeitadas as peculiaridades regionais e locais.

Analisando os referidos objetivos fundamentais, percebe-se claramente que a proposta de cooperação executiva introduzida pela Lei Complementar n. 140/2011 se afina ao marco normativo socioambiental da Carta Política de 1988 e ao dever de garantia do mínimo existencial socioambiental, porquanto reconhece, dentre as finalidades básicas da administração do ambiente pelo Poder Público, a proteção da qualidade ambiental e do equilíbrio ecológico, atrelando-os à erradicação da pobreza, ao respeito à dignidade humana e ao fomento do desenvolvimento socioeconômico.

Os objetivos fundamentais da cooperação federativa a serem exercidos no âmbito das competências administrativas comuns em matéria ambiental, de acordo com a moldura definida nos artigos $7^{\circ}$ a $10^{\circ}$ da Lei Complementar n. 140/2011, e por meio dos instrumentos de cooperação supra referidos, buscam, portanto, sempre o bem-estar socioambiental. Em outras palavras: o dever de cooperação entre entes federativos no exercício da competência comum em matéria ambiental objetiva, ao fim e ao cabo, garantir o bem-estar socioambiental individual e coletivo em todas as suas dimensões, de modo a consolidar um modelo federativo de cooperação com foco na sustentabilidade.

Parte-se agora, para uma breve análise sobre a importância da cooperação federativa no âmbito executivo para a concretização do objetivo acima delineado. 


\section{A COOPERAÇÃO FEDERATIVA E OS DESAFIOS PARA IN- CORPORAÇÃO DO PARADIGMA DA SUSTENTABILIDADE}

O Princípio da Cooperação é considerado um dos princípios informativos do Direito Ambiental, embora não seja exclusivo desse ramo do Direito.

Trata-se de princípio que, segundo Cristiane Derane ${ }^{24}$, " [...] faz parte da estrutura do Estado Social" e orienta o desenvolvimento político por meio da execução de políticas públicas voltadas ao bem-estar individual e coletivo. A cooperação também exige uma atuação conjunta do Estado e da sociedade na proteção do meio ambiente, impondo-lhes uma distribuição de deveres fundamentais.

A cooperação, segundo a lição de Michael Kloepfer ${ }^{25}$, pode ser compreendida no âmbito da proteção jurídica do ambiente em diferentes sentidos: a) como princípio cooperativo de política ambiental, envolvendo a colaboração entre Estado e sociedade; b) como princípio cooperativo entre ser humano e natureza, inspirado na filosofia da natureza que supera uma visão excessivamente antropocêntrica da proteção do ambiente e concede à natureza uma condição jurídica própria, e que justamente por isso, encontra obstáculos; c) como princípio de cooperação internacional entre os Estados nacionais, visando encontrar soluções para os problemas que ultrapassem a esfera interna de um único Estado; e d) como princípio cooperativo no plano da organização interna de um Estado.

Esse último sentido dado ao Princípio da Cooperação é o mais relevante quando o foco da análise se volta para a estrutura federativa de uma nação. A esse respeito, Krell ${ }^{26}$ destaca:

\footnotetext{
Na maioria dos países com estrutura federativa, a produção de políticas públicas bem-sucedidas depende cada vez mais da coordenação das ações de níveis de diferentes governos autônomos (shared decision making), o que torna a montagem de um verdadeiro Welfare State mais complexa, "envolvendo jogos de cooperação e competição, acordos, vetos e decisões conjuntas entre os níveis de governo". O modelo do Estado federado não é uma "tábua de salvação", mas um mecanismo dependente de uma série de condições para ser bem-sucedido.
}

\footnotetext{
${ }^{24}$ DERANI, 2008, p. 141.

${ }^{25}$ KOEPFER, 2010, p. 70.

${ }^{26}$ KRELL, 2008, p. 40.
} 
A cooperação e a coordenação das ações federativas, objetivando garantir a concretização do mínimo existencial socioambiental estão diretamente ligadas ao Princípio da Subsidiariedade, afinal essas ações coordenadas devem observar e promover, como acentua $\mathrm{Krell}^{27}$, a "diversidade regional e a descentralização das instâncias de decisão". Assim, a atuação em nível governamental superior somente se dará quando o inferior mostrar incapacidade de cumprir a respectiva tarefa de forma eficaz ${ }^{28}$.

Ainda, uma efetiva cooperação federativa no âmbito executivo, voltada à garantia de um mínimo existencial socioambiental, não pode se furtar ao enfrentamento de problemas tradicionais do Estado de Direito brasileiro, os quais ensejam cada vez mais desigualdade socioambiental, tais como: a segregação socioespacial ditada pelas forças de mercado, que faz com que as fontes de risco e impacto ambiental se concentrem nas áreas habitadas por grupos sociais vulneráveis, sem voz política e sem poder econômico que lhes permita migrar para fora desse circuito de risco socioambiental; e a desigual aplicação da legislação ambiental, já que, não raro, a legislação protetiva do ambiente é aplicada como rigor aos pequenos agricultores, extrativistas, pescadores, mas flexibilizada quando interesses de grandes corporações econômicas ingressam no "jogo político-decisório". ${ }^{29}$

Um referencial a ser considerado é o modelo de Estado de Direito sustentável traçado por Freitas ${ }^{30}$, que, em síntese, apresenta as seguintes características: a) seja viabilizador de políticas públicas direcionadas a uma economia de baixo carbono com foco no bem-estar socioambiental das gerações presentes e futuras; $b$ ) seja não patrimonialista, embora atento à "tragédia dos comuns", por meio de políticas e metas alicerçadas na ideia de um desenvolvimento durável; c) seja cumpridor de suas funções regulatórias e de polícia ambiental; d) seja fomentador dos espaços para a participação na vida política e capaz de assegurar acesso à justiça, à informação e à tomada de decisões em matéria socioambiental; e) seja garantidor da segurança jurídica e da confiança nas relações públicas e privadas; f) seja prestador contínuo de serviços públicos, independente de interesses político-partidários; e g) seja observador da priorização exigida pelos direitos fundamentais e pelo mínimo existencial socioambiental mesmo no campo

\footnotetext{
${ }^{27}$ KRELL, 2008, p. 43.

${ }^{28}$ KRELL, 2008, p. 14.

${ }^{29}$ ACSELRAD; MELLO; BEZERRA, 2009, p. 78.

${ }^{30}$ FREITAS, 2012, p. 267-269.
} 
da discricionariedade administrativa.

Um Estado de Direito com tais características por certo reconhecerá na sustentabilidade um direito fundamental ao futuro que redefine os contornos normativos de todos os demais direitos e deveres fundamentais.

\section{CONSIDERAÇÕES FINAIS}

As ideias que nortearam o presente ensaio somam-se às incessantes buscas tecidas no campo doutrinário por referenciais normativos capazes de proporcionar um aperfeiçoamento do sistema federativo brasileiro, notadamente no que diz respeito à tutela de direitos fundamentais. Neste ensaio, utilizaram-se como referência os direitos fundamentais socioambientais, dada sua significância no atual marco normativo constitucional brasileiro, porém outras poderiam ser as abordagens tendo em vista a amplitude dos problemas no cenário social brasileiro e a incapacidade estatal de implementar políticas públicas mais eficazes.

A cooperação federativa que norteia as políticas públicas socioambientais no Brasil deve, portanto, ter como referência as noções paradigmáticas de mínimo existencial e de bem-estar socioambiental. Os deveres de proteção do Estado em matéria socioambiental decorrentes do atual marco normativo constitucional brasileiro incorporam, assim, o referencial não menos paradigmático da sustentabilidade como seu objetivo fundamental. Do contrário, o Estado de Direito brasileiro assume-se como um Estado insustentável, legitimador de injustiças ambientais e de iniquidades socioeconômicas. Um Estado contraditório, porquanto incapaz de concretizar, no plano fático, seu marco normativo constitucional. Um Estado de não Direito. Um Estado sem futuro.

O paradigma da sustentabilidade, que tem na multidimensionalidade do bem-estar o fio condutor que preenche o conteúdo normativo do mínimo existencial socioambiental, também implica uma releitura (ampliada) das construções dogmáticas e jurisprudenciais que versam sobre a responsabilidade do Estado em face da ação estatal insuficiente ou da omissão estatal na tutela dos direitos fundamentais socioambientais.

Mas é forçoso reconhecer que ainda estamos longe do ideal que aqui se projeta. Contudo, para além de mera retórica argumentativa, pondera-se que a cooperação federativa pautada pelo referencial do mínimo existencial socioambiental e pela multidimensionalidade do bem-estar tem a contribuir na edificação dessa almejada mudança estrutural e sistêmica. 
Superar o plano do discurso referente à consolidação do Estado Socioambiental Sustentável e alcançar o plano fático é o desafio atual da Ciência do Direito, mas também das demais Ciências e de cada um de nós.

\section{REFERÊNCIAS}

ACSELRAD, Henri; MELLO, Cecília Campello do Amaral; BEZERRA, Gustavo das Neves. O que é Justiça Ambiental. Rio de Janeiro: Garamond, 2009.

ANDERSON. George. Federalismo: uma introdução. Tradução: Ewandro Magalhães Júnior e Fátima Guerreiro. Rio de Janeiro: FGV, 2009.

CANOTILHO, José Joaquim Gomes. Estado de direito. Lisboa: Gradiva, 1999.

CHEVALIER, Jaques. O Estado de Direito. Belo Horizonte: Fórum, 2013.

DERANI, Cristiani. Direito ambiental econômico. São Paulo: Saraiva, 2008.

FARIAS, Paulo José Leite. Competência federativa e proteção ambiental. Porto Alegre: Fabris, 1999.

FREITAS, Juarez. Sustentabilidade: direito ao futuro. 2. ed. Belo Horizonte: Fórum, 2012.

KOEPFER. Michael. A caminho do Estado Ambiental? A transformação do sistema político e econômico da República Federal da Alemanha através da proteção ambiental especialmente desde a perspectiva da ciência jurídica. In: SARLET, Ingo Wolfgang (Org.). Estado socioambiental e direitos fundamentais. Porto Alegre: Livraria do Advogado, 2010.

KRELL. Andreas J. Leis de normas gerais, regulamentação do Poder Executivo e cooperação intergovernamental em tempos de Reforma Federativa. Belo Horizonte: Fórum, 2008.

MACHADO, Paulo Affonso Leme. Direito Ambiental Brasileiro. 21. ed. São Paulo: Malheiros, 2013.

MOLINARO. Carlos Alberto. Direito Ambiental: proibição de retroces- 
so. Porto Alegre: Livraria do Advogado, 2007.

MUKAI, Toshio. A Lei Complementar n. 140 de 08 de dezembro de 2011, que fixa diretrizes para a cooperação entre os entes federativos em matéria ambiental. Fórum de Direito Urbano e Ambiental - FDUA, Belo Horizonte, ano 10, n. 60, p. 88-94, nov./dez. 2011.

NOVAIS, Jorge Reis. Contributo para uma Teoria do Estado de Direito. 2. ed. Coimbra: Almedina, 2006.

SARLET, Ingo Wolfgang; FENSTERSEIFER, Tiago. Estado socioambiental e mínimo existencial (ecológico?): algumas aproximações. In: SARLET, Ingo Wolfgang (Org.). Estado socioambiental e direitos fundamentais. Porto Alegre: Livraria do Advogado, 2010.

. Direito Constitucional Ambiental: constituição, direitos fundamentais e proteção do ambiente. 3. ed. São Paulo: Revista dos Tribunais, 2013.

STIGLIZ, Joseph E.; SEM, Amartya; FITOUSSI, Jean-Paul. Report by the Commission on the Measurement of Economic Performance and Social Progress. Commission on the Measurement of Economic Performance and Social Progress, Paris, 2009. Disponível em: <http://www.stiglitzsen-fitoussi.fr/documents/rapport_anglais.pdf $>$. Acesso em: 20 jun. 2013.

STIGLITZ, Joseph E. EI precio de la desigualdad: el 1\% de la población tiene lo que 99\% necesita. Traducción de Alejandro Pradera. Madrid: Taurus Pensamiento, 2012.

TOMIO, Fabrício Ricardo de Limas; ORTOLAN, Marcelo Augusto Biehl; CAMARGO, Fernando Santos. Análise comparativa dos modelos de repartição de competências legislativas e administrativas nos Estados federados. Revista da Faculdade de Direito - UFPR, Curitiba, n. 51, 2010, p. 73-100. Disponível em: <http://ojs.c3sl.ufpr.br/ojs2/index.php/direito/article/viewFile/30686/19807>. Acesso em: 18 jun. 2013.

Recebido: 17/10/2013

Aceito: $27 / 11 / 2013$ 